\title{
Intoxicação Alimentar um Problema de Saúde Pública
}

Nicole Blanco Bernardes ${ }^{1}$, Larissa de Souza Facioli ${ }^{2}$, Maria Luzia Ferreira ${ }^{3}$, Raissa de Moura Costa ${ }^{4}$, Ana Cristina Fonseca de Sá ${ }^{5}$.

\begin{abstract}
Resumo: Este trabalho foi escrito devido a importância de apresentar maior conhecimento as pessoas, não somente da área da saúde, da importância do cuidado com os alimentos para evitar o aumento do número de ocorrência de casos de toxinfecção alimentar, principalmente pela Salmonella spp. Dentro da contaminação do alimento podese ter a infecção, intoxicação e a toxinfecção alimentar, nos três tipos há diversos fatores que facilitam a ocorrência desses casos, que vão desde a precariedade no saneamento básico até a falta de cuidado e fiscalização dos alimentos, Diferenciando intoxicação, de infecção e de toxinfecção alimentar, mostrar os alimentos, microrganismos e os sintomas mais frequentes, quais os meios de contaminação, o papel da vigilância sanitária, as buscas foram realizadas em duas bases de dados bibliográficos, sendo estes SciELO (Scientific Eletronic Libray Online) e Google Acadêmico,foram selecionados artigos do período de 1996 a 2018.
\end{abstract}

Palavras-chave: Intoxicação alimentar. Infecção. Saúde pública.

\section{Food Poisoning a Public Health Problem}

\begin{abstract}
This work was published because of the importance of the people with the highest number of cases reporting food poisoning cases, especially Salmonella spp. Contamination of food can be an interference, poisoning and food poisoning, several, several factors that facilitate the absence of cases, ranging from a precariousness in basic sanitation to a lack of care and inspection of food, differentiation intoxication, of infection and food toxinfection, such as food, microorganisms and the most frequent symptoms, such as means of contamination, the role of sanitary surveillance, as the searches were exposed in two bibliographic databases, these being SciELO and Google Scholar, were included in the period from 1996 to 2018.
\end{abstract}

Keywords: Food poisoning. Infection. Public health.

\section{Introdução}

Um dos principais problemas públicos de saúde do mundo são as doenças causadas por alimentos. Elas ocorrem tanto em países desenvolvidos quanto subdesenvolvidos apresentando uma taxa significativa de morbimortalidade. Podem ser causadas pelo consumo de alimentos

\footnotetext{
${ }^{1}$ Graduada em biomedicina. Docente na Universidade Estadual de Minas Gerais (UEMG) - Unidade Acadêmica de Passos desde de 2010. Mestranda da Universidade de São Paulo USP na área de ciências da saúde e especialista em biomedicina estética e imagenologia. Contato: nicoleblanco100@yahoo.com;

${ }^{2}$ Graduanda do curso de Biomedicina pela UEMG. Contato: larissafacioli@gmail.com

${ }^{3}$ Graduanda do curso de Biomedicina pela UEMG. Contato: maluferreira3@ hotmail.com

${ }^{4}$ Graduanda do curso de Biomedicina pela UEMG. Contato: moura_raissa@

5 Graduanda do curso de Biomedicina pela UEMG. Contato: bfaninha31 @ gmail.com
} 
contaminados por microrganismos patogênicos, toxinas microbianas ou substâncias químicas (SHINOHARA; et. al, 2008).

Dentro da contaminação do alimento pode-se ter a infecção, intoxicação e a toxinfecção alimentar. Nos três tipos há diversos fatores que facilitam a ocorrência desses casos, que vão desde a precariedade no saneamento básico até a falta de cuidado e fiscalização dos alimentos, tanto no processo de fabricação quanto manuseio (FRANCO e LADGRAF, 2005).

Mais da metade dos casos de intoxicação alimentar é causado por bactérias, sendo as principais, Salmonella spp, Staphylococcus aureus e Clostridium perfringens, que provocam, na maioria das vezes, sintomas como diarreia, vômitos e dores abdominais, porém caso haja um agravamento o paciente pode vir a óbito (ALMEIDA, 2008).

A Salmonella spp foi descoberta por Daniel Salmon que isolou o microrganismo pela primeira vez em suínos. Ela é muito frequente em produtos agrícolas não processados, onde ocorre o contágio por meio da água impura e em alimentos de origem animal. Nos seus derivados a contaminação ocorre mediante a exposição direta, já para a carne isso ocorre no processo de abate (MINISTÉRIO DA SAÚDE, 2011).

Quando duas ou mais pessoas apresentam os mesmos sintomas após a ingestão de alimentos da mesma origem tem-se um surto alimentar. A probabilidade de este ser reconhecido e notificado pelas autoridades de saúde depende, entre outros fatores, da comunicação dos consumidores, dos relatos dos médicos e das atividades de vigilância sanitária das secretarias municipais e estaduais de saúde (NUNES; et. al, 2017).

No Brasil, os órgãos responsáveis pela notificação da intoxicação alimentar é a Vigilância Sanitária (VISA), que é coordenado pela Agência Nacional de Vigilância Sanitária (ANVISA) e trabalham concomitantemente com a Vigilância Epidemiológica. Elas possuem o papel de garantir maior qualidade dos produtos alimentícios e dos pacientes, e para isso criouse a RDC n²16, que visa às boas práticas para serviços de alimentação e condições higiênicosanitárias (SILVA; et. AL, 2008).

Os alimentos com maior índice de casos de contaminação são os naturais devido a possíveis microrganismos patogênicos existentes na água ou no solo, ao uso exacerbado dos agrotóxicos e pela má higienização dos manipuladores. Em uma pesquisa realizada nos Estados Unidospelo Centro de Ciência de Interesse Público foi observado que os maiores registros de intoxicação ocorreram pelo consumo de folhas verdes, ovos, atum e batata (Moraes, 2014). 
Diante disso, o objetivo do trabalho é diferenciar intoxicação, de infecção e de toxinfecção alimentar, mostrar quais são os alimentos, microrganismos e os sintomas mais frequentes, os meios de contaminação, o papel da vigilância sanitária e epidemiológica e dar ênfase a Salmonella spp. Portanto o trabalho objetivou diferenciar intoxicação, de infecção e de toxinfecção alimentar, mostrar os alimentos, microrganismos e os sintomas mais frequentes, quais os meios de contaminação, o papel da vigilância sanitária e epidemiológica e dar ênfase a Salmonella spp apresentando sua taxonomia, característica gerais, clínicas e patogênicas e sua epidemiologia.

\section{Metodologia}

As buscas foram realizadas em duas bases de dados bibliográficos, sendo estes SciELO (Scientific Eletronic Libray Online) e Google Acadêmico. Foram selecionados artigos do período de 1996 a 2018 uma vez que este trabalho elucidou a toxinfecção alimentar. A linguagem adotada para tal pesquisa foi o português. Nas buscas foram utilizados os seguintes termos: infecção alimentar, salmonella spp, espécies e subespécies de salmonella, ciclo biológico, vigilância sanitária, vigilância epidemiológica, intoxicação alimentar, toxinfecção alimentar, salmonelose, doenças transmitidas por alimentos, sintomas, profilaxia, contaminação de alimentos, toxinas, bactérias, fungos e vírus. No total foram utilizadas vinte e quatro referências, sendo artigos, livros, revistas e sites.

\section{Doença transmitida por alimento (DTA)}

Segundo o Ministério da saúde a DTA é definida como sendo a: "Síndrome geralmente constituída de anorexia, náuseas, vômitos e/ou diarréia, acompanhada ou não de febre, relacionada à ingestão de alimentos ou água contaminados.”

Dentro da contaminação alimentar nós podemos classificar três tipos de casos diferentes: a infecção, a intoxicação e a toxinfecção. 
A infecção alimentar é quando um indivíduo ingere algum alimento que está contaminado com células de microrganismos patogênicos (bactérias) que irão se aderir e se multiplicar no trato intestinal (LIMA; SOUSA, 2002).

Intoxicação se refere tanto ao consumo de alimentos contaminados com toxinas microbianas, que foram liberadas no alimento durante o processo de proliferação dos microrganismos, quanto á contaminação por agrotóxicos ou substâncias químicas presentes no alimento. Já a toxinfecção ocorrem pela ingestão de alimentos contaminados com células microbianas e toxinas ou substâncias tóxicas presentes. (FRANCO e LADGRAF, 2005).

\section{Notificação da Intoxicação Alimentar}

A expansão dos mercados de consumo, a globalização econômica, o aumento na ingestão de alimentos industrializados e as modificações dos hábitos alimentares, levaram ás alterações no perfil epidemiológico de afecções transmitidas por alimentos, no entanto essas doenças continuam sendo umas das principais causas de morbidade nos países. Em 2008, as patologias infecciosas do aparelho digestivo e parasitárias correspondiam a 9,2\% do total de casos de mortalidade no Brasil (SHINOHARA; et. al, 2008).

A subnotificação dos casos de intoxicações oligossintomáticas ainda é muito frequente, principalmente pelo fato de que o alimento na maioria das vezes não apresenta gosto, cheiro ou aparência diferente das normais e os sintomas muitas vezes são amenos, fazendo com que as pessoas só procurem alguma ajuda quando esses são agravados. Quando se tem a procura para o atendimento médico, a maioria dos casos de intoxicação alimentar não é identificada, porém quando isso ocorre, a maioria deles é causada pela Salmonella, como pode ser observado no gráfico 1. (KARRAS, 2000).

Quando se têm a denúncia de um surto por DTA alguns órgãos, como ANVISA, VISA e VE, devem ser notificados para que medidas específicas sejam tomadas, como a coleta de informações básicas para o controle do surto, diagnóstico da doença e identificação do agente etiológico e a provável fonte de contaminação. O funcionamento da detecção e investigação está esquematizado na imagem 1 (MINISTÉRIO DA SAÚDE, 2016). 
A Agência Nacional de Vigilância Sanitária (ANVISA) tem a função de proteger a saúde da população, por meio do controle sanitário da produção e do consumo de produtos e serviços submetidos à Vigilância Sanitária, incluindo a inspeção dos ambientes, dos processos, dos insumos e das tecnologias a eles aplicados (PORTAL ANVISA, 2018).

A Vigilância Sanitária participa da atividade de campo, realizando a inspeção sanitária do local envolvido com o surto de DTA para a identificação de pontos críticos do alimento suspeito e adoção de medidas de intervenção e controle, assim ela informa a Vigilância Epidemiológica (VE) (MINISTÉRIO DA SAÚDE, 2010).

A Vigilância Epidemiológica identifica os doentes, assim determina o período de incubação para a elaboração de hipóteses em relação ao agente etiológico e o alimento suspeito. Com essa avaliação há o conhecimento do risco que os infectados foram expostos, quais são os alimentos suspeitos e os pontos críticos não controlados que possibilitaram o desencadeamento do surto. Então ela propõe medidas de prevenção e controle, divulga os resultados da investigação epidemiológica as áreas envolvidas e a população para que novos surtos não aconteçam (MINISTÉRIO DA SAÚDE, 2018).

Gráfico 1: Notificação de Intoxicação Alimentar

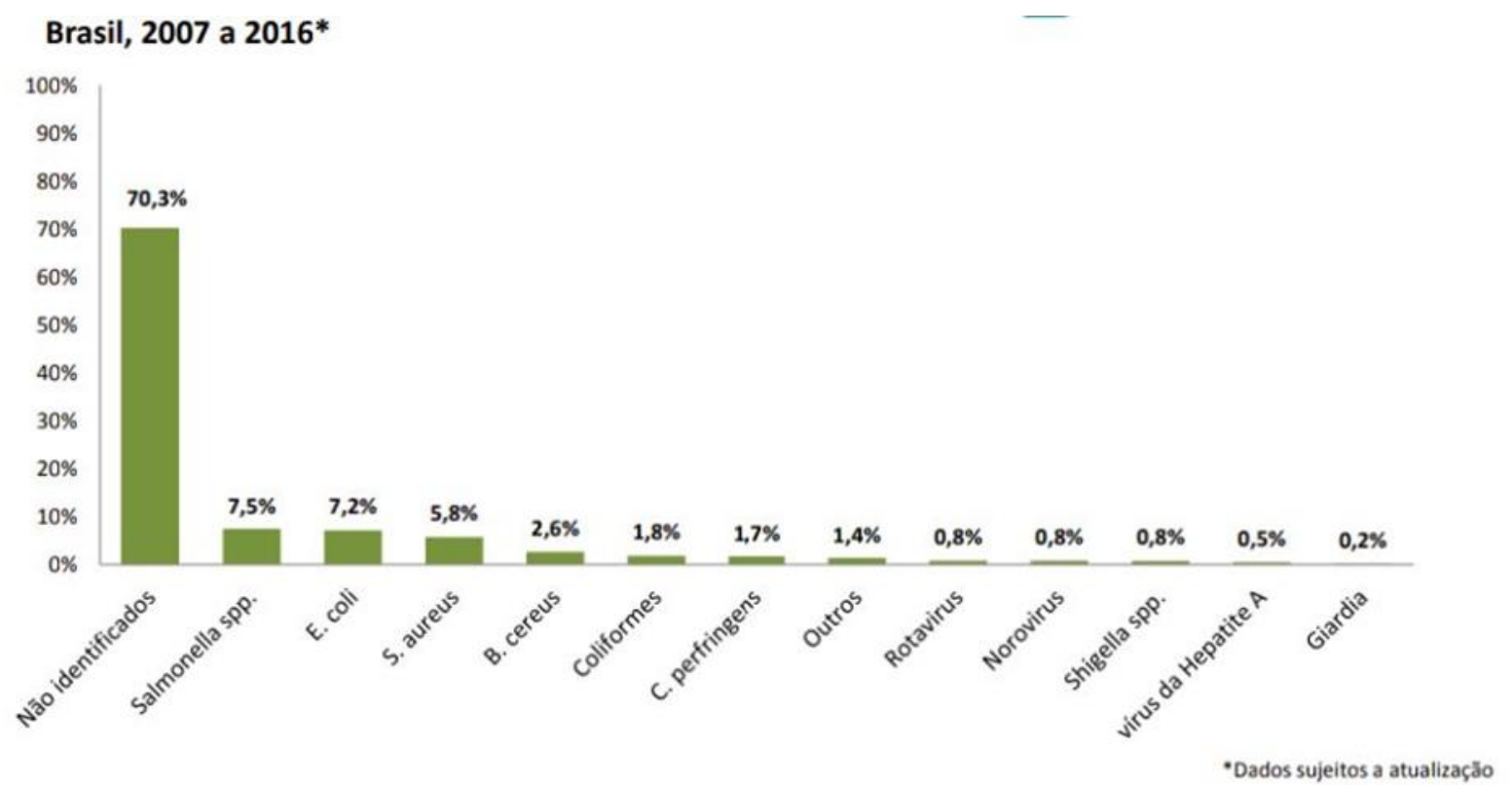

Fonte: Fonte Sinan/SVS 
Figura 1: Funcionamento da detecção e investigação da Intoxicação Alimentar

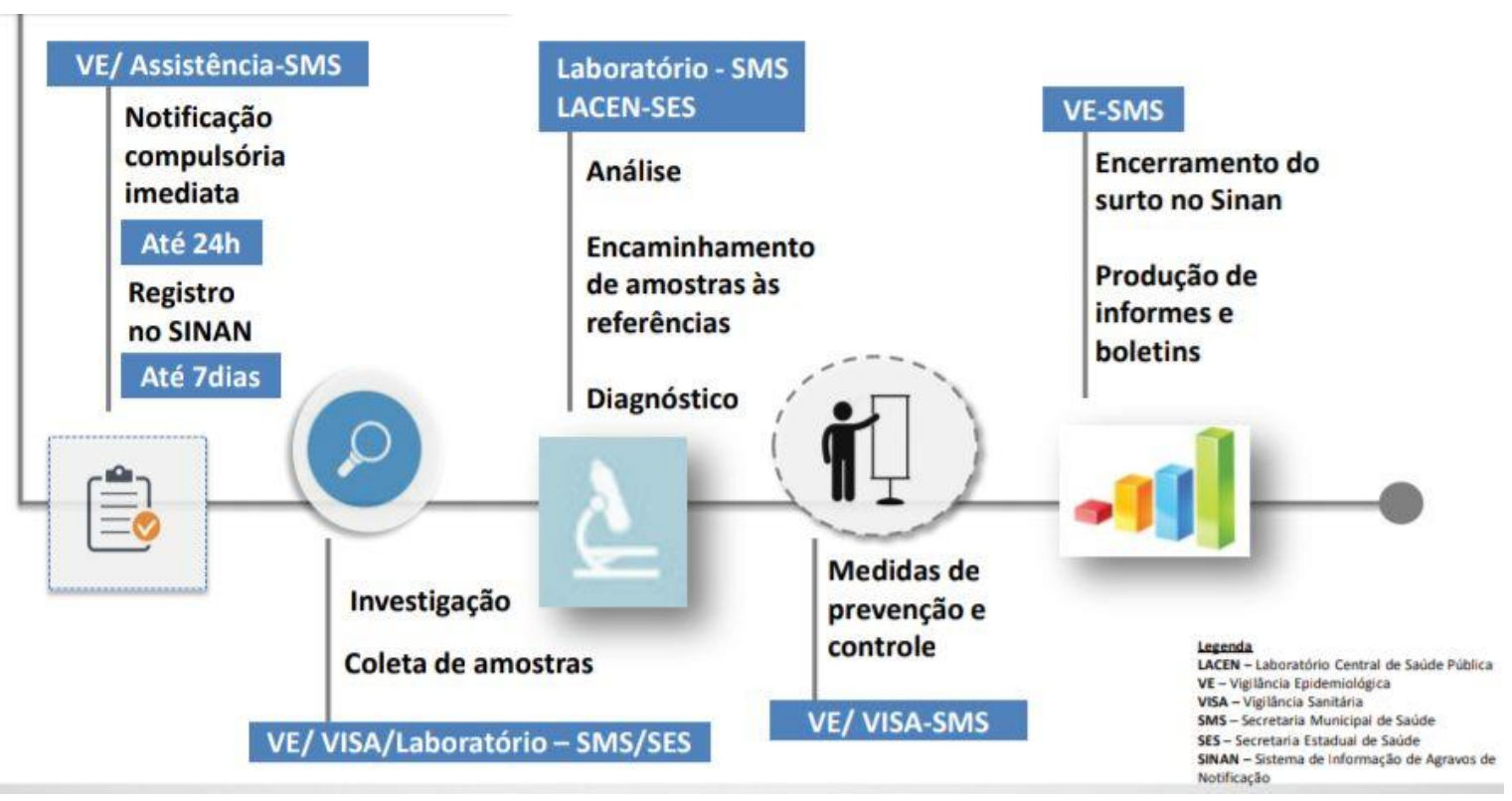

A contaminação dos alimentos pode ocorrer desde o momento do seu plantio, por meio do uso excessivo de agrotóxicos, de mãos mal higienizadas e por meio solo e água contaminados, ou até mesmo no momento do consumo do produto, com o armazenamento e refrigeração incorreta desse. As contaminações alimentares podem ocorrer basicamente por agentes químicos, físicos e biológicos (SILVA, 2012).

Agentes Químicos são aqueles advindos de resíduos de agrotóxicos utilizados em lavouras, presença de antibióticos para tratamento de enfermidades em animais, resíduo de agentes sanitizantes incorporados na indústria, dosagem excessiva de aditivos, incorporação de materiais presentes nas embalagens, geração de compostos tóxicos em alimentos (MACHADO e SILVESTRE, 2005).

Agentes Físicos podem ocorrer pela presença de metais, lascas de madeira, Areia, Cabelo e diversos objetos utilizados na manipulação ou acessórios de funcionários que não praticam Boas Práticas de Fabricação (BPF) (MACHADO e SILVESTRE, 2005).Agentes Biológicos os principais são os vírus, protozoários, bactérias, parasitas, fungos e toxinas microbianas (SHINOHARA; et. al, 2008). 


\section{Salmonella}

A salmonella é um gênero pertencente da família Enterobacteriaceae de habitat trato intestinal de animais. São bacilos do tipo Gram-negativos que não produzem esporos, são anaeróbios e possuem vários tipos diferentes que são identificados por sua composição de antígenos de superfície (como observado na Tabela 1), sendo antígenos somáticos (Opolissacarídeos), flagelares (H- proteína) e capsulares (Vi) (FRANCO E GONÇALVES, 2002).

Tabela 1: Esquema abreviado de Kauffman-White

\begin{tabular}{|c|c|c|c|c|}
\hline \multicolumn{5}{|c|}{$\begin{array}{c}\text { Esquema Abreviado de Kauffmann-White para Classificação de Salmonella } \\
\text { Fórmula Antigênica }\end{array}$} \\
\hline \multirow[t]{2}{*}{ Sorotipo } & \multirow[t]{2}{*}{ Grupo } & Antígeno $O$ & \multicolumn{2}{|c|}{ Antígeno $\mathrm{H}$} \\
\hline & & & Fase 1 & Fase 2 \\
\hline S. paratyphi A & A & $1,2,12$ & a & - \\
\hline S. paratyphi B & B & $1,4,5,12$ & b & 1,2 \\
\hline S. typhimurium & & $1,4,5,12$ & $\mathbf{i}$ & 1,2 \\
\hline S. agona & & 4,12 & $f, g, s$ & - \\
\hline S. derby & & $1,4,5,12$ & $f, g$ & $1,2^{*}$ \\
\hline S. cholerasuis & $\mathrm{C}_{1}$ & 6,7 & c & 1,5 \\
\hline S. oranienburg & & 6,7 & $\mathrm{~m}, \mathrm{t}$ & - \\
\hline S. infantis & & 6,7 & $r$ & 1,5 \\
\hline S. newport & $\mathrm{C}_{2}$ & 6,8 & $e, h$ & 1,2 \\
\hline S. typhi & $\mathrm{D}_{1}$ & $9,12, \mathrm{Vi}$ & d & - \\
\hline S. anatum & $\mathrm{E}_{1}$ & 3,10 & $e, h$ & 1,6 \\
\hline
\end{tabular}

Fonte: Tabulsi, 1989/ Franco e Ladgraf, 2005- Microbiologia dos alimentos

Seu pH ideal para reprodução fica em torno de 7 e a temperatura varia de 35 a $37^{\circ} \mathrm{C}$, sendo a mínima de $5^{\circ} \mathrm{C}$ e a máxima de $47^{\circ} \mathrm{C}$ ( são bactérias termo sensíveis; a pasteurização é suficiente para desnaturar suas células e as baixas temperaturas dificultam sua multiplicação), o que pode variar para cada soro tipo (FRANCO e LADGRAF, 2005).

As doenças mais comuns são divididas em três grupos: febre tifóide (Salmonella typhi), febres entéricas ( $\mathrm{S}$. paratyphi $\mathrm{A}, \mathrm{B}$ e $\mathrm{C}$ ) e as salmoneloses (gastroenterite) (FRANCO e LADGRAF, 2005). 
A febre tifóide é transmitida de pessoa pra pessoa por meio da contaminação de água ou alimentos com material fecal humano. É causada pela Salmonella typhi que afeta apenas os seres humanos, que podem se tornar um reservatório de disseminação da infecção, uma vez que a bactéria é transportada pelos vasos sanguíneos e atingem possíveis órgãos como fígado, vesícula biliar (seu habitat mais comum), medula óssea e bexiga. Seu período de incubação é de 7 a 21 dias e seus sintomas podem durar até oito semanas e inclui septicemia, febre alta, diarréia, vômitos, cefaléia e pode levar o paciente a óbito (SOUZA, et. al, 2010).

A febre entérica é mais amena do que a febre tifóide, porém pode evoluir para septicemia ou gastroenterite. É causada pela Salmonella paratyphi com um período de incubação de 6 a 48 horas e pode ser transmitidos principalmente por leite, vegetais crus, mariscos e ovos. Seus sintomas duram em média três semanas e dentre eles se podem citar dores abdominais, diarréia, febre baixa e vômitos (SOUZA, et. al, 2010).

A gastroenterite pode ser classificada como infecções entéricas causadas por outras salmonelas, sendo mais comuns os sorotipos enteritidis, typhimurium e newport. Seu período de incubação é de 12 a 36 horas e seus sintomas permanecem de dois a três dias que incluem dores abdominais, vômito e diarreia (SOUZA, et. al, 2010).

Gráfico 2: Principais sintomas manifestados na contaminação pela Salmonella

\section{Brasil, 2007 a 2016*}

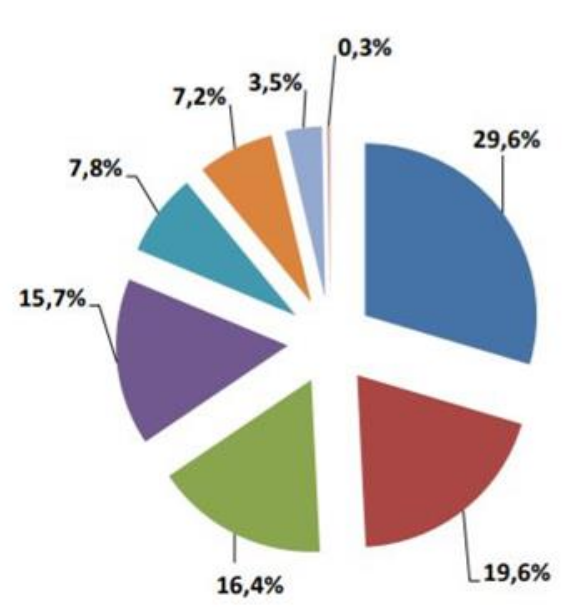

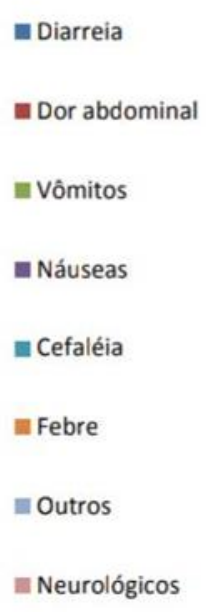

neurológicos

Fonte: Sinan/SVS 


\section{Diagnóstico}

Um grande obstáculo para se obter o controle das contaminações por Salmonella é o diagnóstico rápido e preciso tanto do alimento quanto da pessoa que está contaminada, e esse processo é feito de forma diferente (SANTOS; et.al, 2013).

Nos alimentos o método de diagnóstico mais usado é o microbiológico convencional, que demora cinco dias para se obter o resultado, porém essa técnica causa algumas dúvidas, já que a Salmonella sofre grandes variações bioquímicas e mutações genéticas (SANTOS, 2001).

Novas técnicas de triagem para detecção de Salmonella em alimentos estão sendo desenvolvidas e estudadas, como a reação em cadeia pela polimerase (PCR) e as técnicas imunológicas como o ensaio imunoenzimático (ELISA), sendo este o mais simples, rápido, sensível, específico, de baixo custo e com alta especificidade (DICKEL; et.al, 2005).

Já nos humanos para ser feito o diagnóstico deve-se levar em consideração os sinais clínicos, o período de incubação e os tipos de alimentos ingeridos. Em paralelo, realiza-se o cultivo para o isolamento de microrganismos a partir de restos de alimentos ou do material clínico do paciente, determinando os sorotipos e/ou fagotipos (CARDOSO E CARVALHO, 2005).

A identificação da Salmonella é realizada por meio de provas bioquímicas e sorológicas, e somente pode ser feita em laboratórios de referência a partir de exames clínicos de sangue, fezes, pus ou uma amostra do reto. Logo após esse processo, se confirmado a bactéria no exame, as mesmas são testadas para verificar quais antibióticos são eficazes (teste de suscetibilidade) (BUSH, 2018).

Vale ressaltar que o diagnóstico correto é importantíssimo para que seja feita a intervenção e o tratamento o mais rápido possível evitando o agravamento da DTA (KARRAS, 2000).

\section{Prevenção e controle}

A prevenção e o controle é uma etapa primordial quando se trata de intoxicação alimentar, uma vez que nem todos os casos são notificados e tratados da melhor maneira. Então 
uma série de cuidados pode ser aplicada para que esses erros não sejam cometidos, são eles (SHINOHARA, et. al, 2008):

- Higienização dos alimentos na produção e acondicionamento;

- Distribuição dos alimentos dentro dos limites de segurança microbiológica;

- Qualidade higiênico-sanitária;

- Vacinação para prevenção da febre tifóide em pessoas que moram em áreas endêmicas, ou que vão viajar para tal área, ou para profissionais que trabalham em área de risco (esgoto);

- Hábitos de higiene pessoal;

- Seleção de matéria-prima, utensílios e equipamento utilizados;

- Utilização de água potável;

- Sistema de tratamento de lixo e esgoto;

- Cozinhar aves, ovos e carnes;

- Desligamento dos portadores assintomáticos da área de produção, até que os mesmos sejam tratados.

\section{Tratamento}

Primeiramente o tratamento consiste em aliviar os sintomas, e é principalmente baseado na reidratação (em casos mais críticos ela é feita por via intravenosa, e nos mais amenos por via oral), no uso de analgésicos e antitérmicos. Em casos mais agravantes (quando existe o risco, ou tem-se bacteremia), é realizado o uso de antibióticos, porém esse pode fazer com que haja o agravamento do quadro clínico do paciente (CARDOSO E CARVALHO, 2005).

\section{Conclusões}

Conforme apresentado no trabalho a Toxinfecção Alimentar ainda é um grande problema público de saúde, isso ocorre pela precariedade no cuidado dos alimentos, principalmente nas fases do plantio, fabricação, manuseio e consumo.

A contaminação dos alimentos por Salmonella spp, mesmo sendo a mais frequente, ainda não possui controle exato dos casos de Toxinfecção devido à falta de notificação, seja por parte dos pacientes ou dos médicos, pois a maioria das vezes os sintomas apresentados como diarreia, vômitos e dores abdominais, podem ser confundidos com outras doenças. 
Para que haja um controle maior desses casos, no Brasil, existem órgãos responsáveis pela notificação e fiscalização da intoxicação alimentar, sendo eles a Vigilância Sanitária, que é responsável por garantir uma melhor condição dos alimentos, a Vigilância Epidemiológica que se encarrega pela qualidade de vida dos pacientes e a ANVISA que coordena as normas a serem cumpridas.

Vale ressaltar que as principais formas de se evitar a contaminação dos alimentos é com a melhor higiene dos manipuladores e equipamentos, a segurança de água tratada e solo não contaminado que são garantidos pelo saneamento básico, um reforço nos órgãos de vigilância e maior notificação dos casos para ter um controle real da situação e investigar a origem do problema.

\section{Referências}

ALLESON, L.; HEALYH, N. 10 Foods Most Likely to Make you sick. 2014 JUL.

ALTEBRUSE, S.F. Cols- The changing Epidemiology of foodborne diseases- The amer journal of mundical sciences.1996 JAN; 311(1): 23-29.

ALVES, A. R. F. Doenças alimentares de origem bacteriana. Universidade Fernando Pessoa. Faculdade Ciência da Saúde. 2012 SET.

Brasil. Ministério da Saúde. Secretaria de Vigilância em Saúde. Manual técnico de diagnóstico laboratorial de Salmonella spp: diagnóstico do gênero Salmonella / Ministério da Saúde. Secretaria de Vigilância em Saúde, Fundação Oswaldo Cruz. Laboratório de Referência Nacional de Enteroinfecções Bacterianas, Instituto Adolfo Lutz. - Brasília: Ministério da Saúde, 2011.60 p. : il. - (série A. Normas e manuais técnicos).

BUSH, L. M. Infecções por Salmonella. Affiliate Associate Professor of Medicine, Universitynof Miami-Miller School of Medicine. 2018.

CARDOSO, T. G.; CARVALHO V.M. Toxinfecção alimentar por Salmonella spp. Rev Inst Ciênci Saúde. 2006; 24(2):95-101.

DICKEL, E.L.; RODRIGUES, L. B.; SANTOS, L. R.; GIRARDELLO, R.; COLUSSI, F.M.; DUARTE, L. F.; PILOTTO, F.; NASCIMENTO, V.P. Microbiologia convencional, ELSA e PCR para detecção de Salmonella em abatedouro de frango totalmente automatizado, semiautomatizado de grande porte e semi-automatizado de pequeno porte. Biblioteca Virtual em Saúde. Secretaria Municipal da Saúde de São Paulo. 2005; 19(132):79-85. 
FRANCO, B. D. G. M.; LANDGRAF, Mariza. Microbiologia dos alimentos. São Paulo: Atheneu, 2005; 1:56-58.

FRANCO, M. R.; GONÇALVES, P. M. R. Shigella: Taxonomia, epidemiologia, isolamento e identificação em alimentos. Revista Higiene Alimentar, São Paulo, v. 16, n. 92/93, p. 26-32, jan/fev. 2002.

JUNAURA, R.B.; LUCIANA, R.S. Intoxicações Alimentares. UFBA Medicina. Cap. 24.

KARRAS, D.S. Incidence of foodborne illnesses: Prelimirany data from the foodborne diasease active surveillance netwok (foodnet). Annals of Emergency Medicine. 2000 JAN; 35(1): 9395 .

LIMA, A. W. O.; SOUSA, C. P. Infecções e intoxicações alimentares. In:m Aspectos daciência e tecnologia de alimentos. 1 ed. João Pessoa, PB: Nova Idéia, 2002;1:175-199.

Ministério da Saúde. Manual Integrado de Prevenção e Controle de Doenças Transmitidas por Alimento. Secretaria de Vigilância em Saúde. 2018.

Ministério da Saúde. Manual Integrado de Vigilância, Prevenção e Controle de Doenças Transmitidas por Alimento. Secretaria de Vigilância Sanitária. Departamento de Vigilância Epidemiológica. 2010.

Ministério da Saúde. Surtos de doenças transmitidas por alimentos no Brasil. Secretaria de Vigilância em Saúde. Departamento de Vigilância das Doenças Transmissíveis. Coordenação Geral das Doenças Transmissíveis. Unidade de Vigilância das Doenças Transmissíveis. 2016 JUN.

PINTO, A. F. M. Doenças de origem microbiana transmitida pelos alimentos. Acessado em 06 de abril de 2018. WWW.ipv.pt/millenum/etc4-1.htm

SANTOS, J. R.; MEZA, S. K. L.; MARTINI, K. C.; NUNES, R. V. A importância do controle da Salmonella na cadeia produtiva de frango de corte. Seientia Agraria Paranaense- SAP. 2013; 12(3):167-174.

SANTOS, L. R. Fagotipagem e Analise por RAPD/PCR (DNA polimórfico amplificado ao acaso) de amostras de Salmonella Enteritidis isoladas de materiais de origem avícola e de alimentos e humanos envolvidos em casos de toxinfeccões alimentares. Tese (Doutorado)Faculdade de Veterinária- Universidade Federal do Rio Grande do Sul. 2001.

SHINOHARA, N. K. S.; BARROS, V. B.; JIMENEZ, S. M. C.; MACHADO, E. C. L.; DUTRA, R. A. F.; FILHO, J. L. L. Samonella spp., importante agente patogênico veiculado em alimentos. Ciência e saúde coletiva. 2008; 1675-1683 p. 
SILVA, R. A. Ciência do Alimento: Contaminação, Manipulação e Conservação dos Alimentos. Monografia- Universidade Tecnológica Federal do Paraná. Diretoria de Pesquisa e Pós-graduação. Especialização em Ensino e Ciência. 2012.

SILVESTRE, A. M. L.; GAGO, D.; PAIXÃO, C.; BRITO, S. Contaminação dos alimentos. Segurança Alimentar na Restauração. Ministério do Trabalho e da Solidariedade Social. 2005. SINAN. Sistema de Informação de Agravos de Notificação. Secretaria de Vigilancia em Saúde. 2016.

Sobre surtos de doenças de transmissão alimentar. Acessado em 18 de abril de 2018. www.portal.saude.sp.gov.br

SOUZA, C. O.; RAMOS, F. L. P.; MATA, C. M.; SANTOS, L. V. S.; LOPES, M. L. Resistência antimicrobiana de Salmonela typhi identificadas no Estado do Pará, Brasil. Rev PAN-AMAZ Saúde, 2010; 1(2):61-65.

Tratamento dos casos de intoxicação alimentar na região de Juiz de Fora- MG, no período 2005/2006 estudo de dados. Revista O Mundo da Saúde São Paulo. 2008; 393-401 p.

\section{Como citar este artigo (Formato ABNT):}

BERNARDES, Nicole Blanco; FACIOLI, Larissa de Souza; FERREIRA, Maria Luzia; COSTA, Raissa de Mour; SÁ, Ana Cristina Fonseca de. Intoxicação Alimentar um Problema de Saúde Pública . Id on Line Rev.Mult. Psic., 2018, vol.12, n.42, p. 894-906. ISSN: 1981-1179.

Recebido: 24/10/2018;

Aceito: $26 / 10 / 2018$ 